\title{
A construção do regionalismo deliberativo-instrumental a partir da cooperação setorial na América Latina (1991-2015)
}

The Building of Deliberative-Instrumental Regionalism:

an Analysis of Sectoral Cooperation in Latin America (1991-2015)

\section{CLARISSA FRANZOI DRI*}

Universidade Federal de Santa Catarina, Florianópolis, Brasil

clarissa.dri@ufsc.br

\section{TIAGO MOCELLIN PITTAS}

Universidade Federal de Santa Catarina, Florianópolis, Brasil mocellin.tiago@gmail.com

DOI: https://doi.org/10.46468/rsaap.14.1.A1

Este artigo visa oferecer um panorama do diálogo do Brasil com sua vizinhança a partir da perspectiva da cooperação regional, propondo um balanço da integração com foco nas dimensões política e social. Para tanto, realizou-se uma categorização exaustiva das normas dos órgãos decisórios do Mercosul, Unasul e CELAC desde sua criação até 2015, a fim de avaliar a evolução dos acordos em cada setor. Com base nos temas mais recorrentes, foram selecionados tópicos para análise que revelam as estratégias da atuação brasileira em seu entorno. Conclui-se pelo legado de um regionalismo deliberativo e instrumentalizado. Os resultados mostram a instrumentalização, por parte do Brasil, de áreas da cooperação regional em prol da afirmação de sua liderança e imagem internacional. Paralelamente, o objetivo anunciado pelos progressismos de levar a integração para além das metas comerciais e econômicas foi parcialmente atingido, proporcionando de fato a estruturação do diálogo regional em novos temas.

South American integration is Brazilian foreign policy's top priority. Brazil recognizes that she is stronger and more influential in global affairs by working closely with her neighbors and by helping promote peace and prosperity in her region. In spite of her continental dimensions and vast natural resources, Brazil made a resolute choice to work for regional (i.e. South American) integration. Closer economic and political relations con-

* As autoras reconhecem a contribuição de duas avaliações anônimas para uma versão anterior deste artigo. 
tribute to growth and stability. It also increases our (Brazil's and South America's) clout in global negotiations.

Celso Amorim, Ministro de Relações Exteriores do Brasil (19931995, 2003-2010) (Amorim, 2010: 227)

\section{Introdução $^{1}$}

Os objetivos anunciados pelo regionalismo latino-americano passaram por mudanças profundas nas últimas décadas. Enquanto nos anos 1980 as metas eram predominantemente ligadas ao retorno à democracia e ao reconhecimento internacional, na década de 1990 o propósito foi criar mercados ampliados no contexto de políticas econômicas neoliberais. Nos anos 2000, as forças de esquerda no poder apresentaram medidas institucionais a fim de fortalecer as dimensões política e social da integração. Esse objetivo foi alcançado? Esse artigo propõe-se a fazer um levantamento dessas iniciativas e avaliar o papel nelas desempenhado pelo Brasil. A análise inicia-se com a fundação do Mercosul, em 1991, e estende-se até o momento da interrupção do ciclo dos progressismos no Brasil e na Argentina, ao final de 2015, quando teve início uma nova fase de diálogo regional mínimo, com características ainda incertas. Secundariamente, o artigo busca também contribuir para a compreensão da proliferação ou superposição de diferentes arenas regionais, sobretudo a partir da década de 2000. Existe uma divisão ou complementação de tarefas entre essas instituições no âmbito das políticas públicas?

Se a integração econômica não foi aprofundada ou alargada com os governos progressistas, outras agendas parecem ter avançado baseadas em uma perspectiva de cooperação (Malamud, 2013: 6). O Mercosul pode ter se aproximado de caminhos de construção de bens públicos regionais guiados por preferências governamentais, que mantêm as decisões no nível nacional, porém permitiriam coordenação ou harmonização em diferentes fases da formulação das políticas (Botto, 2011). Esse também pode ser o caso de outros grupos regionais revitalizados durante o período de regionalismo aberto nos Andes e na América Central, que encontram dificuldades em consolidar um mercado comum, mas experimentaram um acentuado conhecimento cultural mútuo, definiram linhas prioritárias para cooperação ou constituíram novos arranjos baseados em uma visão simi-

As autoras agradecem as agências CNPq e CAPES do governo brasileiro pelo suporte financeiro para a pesquisa, por meio do Edital Universal, bolsa de iniciação científica, bolsa de mestrado e custeio para a pós-graduação. 
lar dos desafios nacionais (Gil e Paikin, 2013). Esse tipo de abordagem vai além da análise institucional ou jurídica do regionalismo, porque põe luz nos conteúdos do diálogo regional e busca avaliar o potencial das respostas oferecidas aos cidadãos pelas estruturas burocráticas responsáveis pelos acordos. $\mathrm{O}$ foco nas matérias presentes na agenda decisória, mais do que nas instituições, facilita também uma análise transversal e comparativa entre diferentes organismos regionais que existem simultaneamente, com os mesmos Estados-membros e com parcela ou totalidade de objetivos similares.

A discussão sobre bens públicos globais também vem ganhando espaço na política internacional nas últimas duas décadas. O conceito originário da economia começou a ser utilizado para a compreensão dos conteúdos e atores do processo de globalização principalmente a partir do final dos anos 1990 (Inge et al., 1999; Albin, 2003; Inge et al., 2003) e recentemente vinculou-se às noções de governança e regulação internacional (Bodansky, 2012). Uma tipologia da oferta dos bens públicos globais foi proposta por Scott Barret (2007). Mercedes Botto (2011) aplicou a expressão aos arranjos da cooperação interestatal no âmbito do Mercosul, comparando bens a políticas públicas regionais. Enquanto efeito ou consequência dos esquemas políticos, as políticas públicas podem ser compreendidas como os bens entregues aos cidadãos em diferentes áreas. Corroborando essa visão, outros estudos surgiram detalhando atores, processos e metas em diversos setores da cooperação regional na América do Sul (Vazquez e Perrotta, 2012; Sarti et al., 2014; Bianculli e Hoffmann, 2016; Racovschik e Raimundi, 2016). É no mesmo sentido que o presente artigo propõe-se a estudar os bens ou políticas públicas regionais. Trata-se de examinar os resultados apresentados pelas organizações na América Latina, indo além dos tratados e instituições. Este trabalho, no entanto, complementa os anteriores por oferecer dados para uma visão sistemática e panorâmica dos acordos alcançados no âmbito do Mercosul, da Unasul e da Comunidade de Estados Latino-americanos e Caribenhos (CELAC). Ademais, a presente pesquisa também se concentra no possível papel do Brasil como catalisador ou parceiro dessa cooperação.

O mapeamento do conteúdo dos acordos firmados regionalmente e a análise do papel do Brasil em sua iniciativa ou continuidade deve contribuir para testar o alcance das interpretações da política externa brasileira como nova, solidária, benigna ou criativa (Amorim, 2011: 265; Amorim, 2010: 225; Maringoni, Schutte e Berron, 2014: 4; Lima, Garcia e Pomar, 2014: 103). Na esfera regional, os dados indicam que o Brasil pode estar próximo de modelos hierárquicos e excludentes tradicionais da política internacional. Isso demonstra que as estratégias brasileiras associadas ao 
soft power não são desprovidas de interesses nem de contradições. Demonstra também que a horizontalidade, que vem caracterizando alguns projetos brasileiros no âmbito da cooperação sul-sul, pode não estar presente em todos os setores de cooperação no âmbito das organizações regionais latino-americanas. Mas isso não significa que a política externa dos governos progressistas não tenha apresentado mudanças significativas com relação aos governos anteriores, em sua atuação nas diferentes regiões do mundo.

Esse artigo visa contribuir para a compreensão sobre como essas mudanças aconteceram no âmbito latino-americano, com base na noção de deliberação. Etimologicamente, a palavra tem origem nas ideias de ponderar, considerar. Na tradição dos estudos políticos, a deliberação está vinculada ao papel de assembleias reunidas para refletir, examinar e discutir publicamente assuntos de interesse coletivo. Neste estudo, a deliberação é utilizada no sentido de debate e confronto pacífico e democrático de ideias que implicam em controle e direito de crítica (Chagnollaud, 1996: 185). Esse tipo de procedimento não é novidade na América Latina, mas nos anos 2000 os canais para esse diálogo parecem ter englobado mais temas e mais Estados da região do que em momentos anteriores. Assim, essa pesquisa explora a ideia segundo a qual o reforço da cooperação regional a partir de meados dos anos 2000 esteve estreitamente vinculado à tentativa de afirmação da liderança brasileira. Como essa tentativa implicou em investimento em espaços deliberativos regionais, ela pode ter ido além desses objetivos estratégicos primordiais brasileiros e criado arenas de diálogo de extrema relevância para a construção da região América Latina e para sua busca de autonomia.

Metodologicamente, a pesquisa pautou-se na coleta e sistematização de todas as normas emanadas por órgãos decisórios do Mercosul, Unasul e CELAC desde sua fundação até 2015. No caso da CELAC, devido à ausência de decisões, declarações e comunicados presidenciais, foram utilizados para complementar os planos de ação apresentados. A base buscou priorizar os atos emanados pelas instâncias decisórias, não incluindo a agenda dos grupos de trabalho e reuniões diversas que acontecem periodicamente em todas as organizações. As normas foram categorizadas e contabilizadas em um registro anual e, no caso do Mercosul, decenal. Em cada uma das organizações, setores ilustrativos da atuação brasileira foram selecionados para análise, com base nos temas mais frequentemente abordados nas normas.

O artigo está organizado da seguinte forma. A primeira parte revisa a literatura recente sobre a relação do Brasil com sua vizinhança e as principais interpretações formuladas para explicar e avaliar a proliferação e superposição de organismos regionais na América Latina. A segunda par- 
te apresenta os resultados da compilação e categorização das decisões aprovadas no Mercosul (1991-2015), na Unasul (2008-2015) e na CELAC (20082015), além da análise de alguns temas com forte presença na agenda regional. A conclusão confirma a instrumentalização do regionalismo por parte do Brasil em prol de outros objetivos de política externa, como indica parte da literatura, mas aponta também para a formação de um regionalismo deliberativo que estrutura espaços de discussão relevantes. Revela, ademais, certa complementaridade nos temas de trabalho das três organizações, que aprofundam ou alargam temas que já vinham sendo trabalhados em outros organismos, ou agregam novas pautas vinculadas aos Estados que não pertenciam às organizações anteriores.

\section{Entre tradição e inovação: os limites do Brasil-potência na política regional}

A política externa ativa e altiva (Amorim, 2014: 32) de Lula, Celso Amorim e equipe gerou inúmeras análises sobre o comportamento internacional do Brasil e sobre as diferenças e semelhanças com outros períodos históricos. Esse interesse deveu-se, em parte, aos discursos dos agentes responsáveis sobre a estratégia de inserção internacional a ser implementada, com prioridade ao multilateralismo, universalismo, diversificação de parcerias e protagonismo nas discussões internacionais. As novas iniciativas de cooperação sul-sul, pautadas na chamada não-indiferença, levaram à expressão "potência emergente e solidária” (Faria e Paradis, 2013), enquanto a tradição de não-intervenção e pacifismo foi reforçada por meio da defesa da "multipolaridade benigna" (Amorim, 2011: 265). Essas características romperiam com políticas anteriores de adaptação a certas normas e regimes internacionais e de maior convergência com as potências centrais (Cervo, 2003; Lima, 2005: 13; Vigevani e Cepaluni, 2007: 291-292). O governo Dilma Rouseff, embora tenha diminuído a intensidade das ações de política externa, não se afastou desses princípios (Malamud, 2011b; Cervo e Lessa, 2014). De modo complementar, outra parte da literatura aponta para uma atuação regional menos inovadora do Brasil, sobretudo no que concerne à reprodução de práticas tradicionais da política internacional no relacionamento centro-periferia. Menos do que questionar as estruturas internacionais, o Brasil estaria buscando chamar a atenção das potências para suas ações e galgar espaço no concerto internacional. Isso se refletiria em suas ambições econômicas extra-regionais e no baixo nível de legitimidade conquistado junto à sua vizinhança. 
A perspectiva dos papeis sociais mostra que as aspirações brasileiras não dependem apenas de suas habilidades e capacidades, mas também do reconhecimento de outros atores. Nesse ponto, o Brasil parece enviar por vezes mensagens divergentes a atores diferentes - por exemplo, a países centrais, a parceiros extracontinentais na cooperação sul-sul ou a Estados fronteiriços-, o que revela as contradições de sua estratégia. Malamud (2011a) aponta o fraco reconhecimento da liderança brasileira pelos Estados latino-americanos. Países de menor população, como o Paraguai, percebem a manutenção de relações de hegemonia e dependência com o Brasil (Lambert, 2016). Potências regionais, como o México, tentam conter a ascensão brasileira (Covarrubias, 2016). Países intermediários, como Argentina, Chile e Venezuela, convivem com a ideia da liderança brasileira, desde que enquadrada pelas instituições regionais (Wehner, 2015). Quando o Brasil se afasta da busca do consenso na região, a contestação pode aumentar. No caso colombiano, a oposição —indireta— vem por meio da construção de novos modelos regionais, como a Aliança do Pacífico (Flemes e Castro, 2016). Essa contestação não é hostil na América do Sul, mas sim uma tentativa de balanceamento do poder da potência regional (Flemes e Wehner, 2015). Em linhas gerais, o potencial de representação internacional da região pelo Brasil é menos reconhecido nos temas econômicos e securitários (Wehner, 2015: 18), embora o peso econômico brasileiro seja muito mais claro do que as capacidades militares (Schenoni e Actis, 2014). Essa menor legitimidade da representação internacional em temas econômicos pode estar ligada ao fato de que alguns países intermediários procuram certa independência econômica do Brasil para fins de light balancing (Russel e Tokatlian, 2016: 28). Esses Estados buscariam, assim, evitar o aumento da diferença de poder relativo na região ao dificultar a emergência do Brasil como potência hegemônica regional.

Nesse ponto, a criação de instituições regionais pode derivar de uma dupla interpretação: meio para consolidar a liderança, a partir da perspectiva brasileira, ou meio para prevenir a hegemonia do Brasil com base no diálogo e na regulação, a partir da perspectiva dos demais Estados. Essa proposta complementa as tentativas atuais de explicação da proliferação e superposição de organizações regionais na América Latina. Ultimamente, essa diversidade de organizações tem sido vista como parte de um complexo de governança regional definido pela elasticidade ou pluralismo institucional (Nolte, 2013 e 2016). Cada organização é entendida como parte de uma arquitetura regional mais ampla, que molda o discurso dos membros e gera normas considerando problemas coletivos e benefícios comuns, o que deveria contribuir para a formação de uma coesão regional ou regionness (Riggirozzi, 2010). A busca pela 
complementaridade nas agendas das reuniões de cúpula do Mercosul, Unasul e Comunidade Andina corrobora esse argumento (Dabène, 2016b). Esse sistema seria capaz de acomodar os diferentes interesses dos Estados, que podem decidir em qual organização despender mais esforços, de acordo com as suas prioridades e o contexto geral. O complexo é, assim, flexível, já que ele pode se expandir para incorporar novas práticas e necessidades dos Estados. Ele é também multidimensional, com a coexistência de áreas de governança formais e informais e instituições com diferentes graus de consolidação e complexidade, além de dinâmico, o que levaria a compromissos de curto prazo, todavia possivelmente mais espontâneos e voluntários.

Assim, se os atores são aqueles que melhor podem decidir os contornos e características do regionalismo, na América Latina isso não dependeria de transferência de soberania e delegação de competências (Weiffen, Wehner e Nolte, 2013: 6). Ao contrário, métodos regionais estariam sendo desenvolvidos explicitamente para que os Estados lidem com questões de interesse comum mantendo a autonomia, inclusive com relação à potência regional. Esses instrumentos incluem busca de espaço em instâncias deliberativas para uma diversidade de Estados interessados, múltiplas arenas negociadoras e diferentes temas inter-relacionados, formando um tipo de regionalismo modular (Gardini, 2015) ou de geometria variável (Nolte e Comini, 2016). Essa perspectiva confirmaria a tendência de retorno da integração econômica dos anos 1990 a um diálogo cooperativo estável (Malamud e Gardini, 2012): não há decisões supranacionais, mas, ao invés disso, políticas compartilhadas em algumas áreas. No entanto, essa cooperação poderia não representar apenas um fim em si, mas ser instrumentalizada para afirmar a liderança ou para conter a liderança.

O marcante traço conjuntural e imediatista de algumas políticas poderia reforçar esse argumento. Estudando o processo de formação da agenda da Unasul, Dabène (2016a) argumenta que essas políticas são contingentes, dependendo principalmente dos contextos políticos e econômicos. Causas estruturais também desempenhariam um papel, como a presença dos governos de esquerda que fazem esforços por uma cooperação menos centrada no comércio. A Unasul, contudo, é principalmente reativa e sua agenda é parcialmente resultante de eventos desordenados seguidos por cúpulas de emergência e esforços na solução de crises (Dabène, 2016a). Apresentando argumentos contrafactuais, o autor mostra que a exclusão do comércio, a inclusão da defesa e a manutenção da democracia dentro dos tópicos prioritários para deliberação consistem em respostas de curto prazo a eventos cruciais, como as negociações comerciais com os Estados Unidos, a guerra ao terror ou crises políticas nacionais. 
Em uma análise conjunta da atuação da Unasul e da Organização dos Estados Americanos (OEA) em episódios de crise da estabilidade democrática, Weiffen (2017) conclui que ambas organizações podem atuar de modo competitivo ou cooperativo, dependendo da dinâmica de poder regional no caso. Nem sempre um cenário competitivo pode ser associado a efeitos negativos, mas ele pode levar à contestação de normas e bloquear as ações positivas desejadas pelas organizações envolvidas. A alta dependência das interações estatais já em andamento para a determinação da dinâmica entre as organizações (Weiffen, 2017) reforça a ideia de que a superposição institucional pode ser explicada pelas estratégias de liderança. A análise empírica deve contribuir para uma conclusão mais precisa sobre as causas e as consequências da pluralidade de instituições regionais, e, portanto, sobre os papeis das potências nesse quadro. Hipoteticamente, considerando um estudo que integra a OEA e os Estados Unidos, o Brasil teria incentivado a criação de diferentes arenas negociadoras procurando canais extras de influência sobre seus vizinhos. Mas os Estados intermediários podem exercer uma força de reação, respaldados pela instituição regional, quando assim o desejarem.

Uma visão menos otimista da proliferação de instituições regionais e da resiliência do regionalismo latino-americano é trazida pela psicologia social. Segundo Dubé e Thiers (2017), as instituições regionais na América Latina podem ter-se tornado um valor em si mesmas, e as dificuldades de defecção estão relacionadas a laços emocionais e custos percebidos de retirada. O grupo também pode pressionar os membros, expressa ou tacitamente, pela manutenção da adesão. Ademais, a dissonância entre os objetivos desejados e os efetivamente atingidos pode ser mitigada com dados e argumentos seletivos, e esse tende a ser o caso quando recursos importantes já foram empregados em certa direção. No entanto, se os resultados são escassos com relação às metas declaradas, as dinâmicas geradas nesses processos negociadores e deliberativos demandam mais atenção.

A diferença, no caso do Brasil, entre a retórica de prioridade para a integração regional e a prática de forte presença em acordos globais, também parece clara na esfera comercial. A partir de um ponto de vista econômico-comercial, em algumas fases as relações extra-regionais podem ser interpretadas como mais vantajosas para países em desenvolvimento, especialmente no tocante à atração de investimentos e à exportação de bens primários. Nesses momentos, as potências regionais podem ausentar-se da cooperação regional a fim de priorizar parcerias globais, e essa defecção traz graves consequências à vitalidade dos processos de integração em curso (Krapohl, Meissner e Muntschick, 2013). A atração econômica 
extra-regional é um dos motivos para o interesse brasileiro crescente na África e na Ásia a partir de 2005, consubstanciado, sobretudo, em redes como BRICS, IBAS e Comunidade dos Países de Língua Portuguesa (CPLP), e para a Parceria Estratégica Brasil-União Europeia. No entanto, a América Latina, com destaque especial para o Mercosul e a Argentina, ainda é um mercado de grande relevância para os produtos industrializados brasileiros e mantém a marca média de destino de $10 \%$ do total das exportações brasileiras ${ }^{2}$. Assim, o comportamento brasileiro focado no âmbito extra-regional nos anos 2000 não tem necessariamente um viés inovador ou imaginativo, mas retoma, em partes — principalmente na exportação de commodities-, a história da política externa brasileira. Mais desafiador seria, por exemplo, considerar seriamente o âmbito regional como alternativa para fomentar um comércio de alto valor agregado em momentos de (re) primarização da pauta exportadora.

Os limites da política latino-americana do Brasil e, sobretudo, de sua liderança regional são também expostos por uma perspectiva construtivista. Quando se considera que a formação dos interesses segue as identidades, a presença ou a construção de uma identidade coletiva regional tornaria essa liderança mais provável. Sendo essa identidade comum quase inexistente na região em elementos estruturais, sistêmicos e discursivos, a atuação brasileira poderia ser melhor definida por hegemonia do que por liderança (Mesquita, 2016). Como hegemon, o Brasil persegue suas estratégias individuais apresentando-as como se fossem coletivas em vez de efetivamente buscar bens coletivos (Mesquita, 2016: 6). Desse modo, o Brasil deixa de oferecer bens públicos que aumentariam a legitimidade de sua atuação regional (Flemes e Wehner, 2015: 167; Burges, 2015). Essa ideia coloca em xeque a hegemonia consensual que pode ter sido buscada pelo Brasil na América Latina (Burges, 2008), pois enfraquece a aceitação dos valores do hegemon pelos vizinhos. Assim, se a conquista da hegemonia regional é um objetivo da política externa brasileira, ela surge como cada vez menos consensual - e mais tradicional-, considerando a perda de credibilidade com relação aos objetivos anunciados.

A classificação do Brasil como hegemon, ao invés de líder latino-americano, aponta na direção de um regionalismo instrumental e reativo, como se a cooperação fosse estruturada para manter a autonomia brasileira. Essa estratégia serviria à manutenção da estabilidade regional por meio da gestão de crises, à promoção da imagem brasileira como líder por meio do

Dados da balança comercial brasileira entre janeiro e agosto/2017 sistematizados pelo Ministério de Desenvolvimento, Indústria e Comércio. Disponível em http:// www.mdic.gov.br/index.php/comercio-exterior/estatisticas-de-comercio-exterior/ balanca-comercial-brasileira-mensal-2. 
aumento das capacidades regionais e da previsibilidade das ações governamentais, e à tomada de posição regional em assuntos delicados, de modo a preservar os governos nacionais, além de atuar como reação contra iniciativas externas indesejadas (Medeiros, Teixeira Jr e Reis, 2017: 118; Lazarou e Luciano, 2015: 15-17). Do ponto de vista institucional, a própria criação do Parlamento do Mercosul em 2005, defendido oficialmente como fomentador da democracia no bloco, já foi apontada como instrumento para afastar a Área de Livre Comércio das Américas (ALCA) (Medeiros e Dri, 2013; Dri, 2014). Do ponto de vista legal, o baixo nível de incorporação das normas do Mercosul nos ordenamentos jurídicos nacionais pode indicar um interesse maior na assinatura e na publicidade dos acordos do que em sua efetiva implementação (Ventura, Onuki e Medeiros, 2012; Arnold, 2016). A prática das "promessas vazias" permite aos Estados membros, por exemplo, aprovar normas de reforço da integração econômica para contornar um momento de crise, sem que essas regras precisem necessariamente entrar em vigência mais tarde (Arnold, 2016: 6).

Esse fato parece estar relacionado com o que Jenne e Schenoni (2015) chamam de regionalismo declaratório, ou seja, a persistência de afirmações retóricas sobre a integração regional. Estudando as falas dos presidentes latino-americanos nas sessões anuais da Assembleia Geral das Nações Unidas, as referências à unidade regional e às instituições do continente são significativas, e são ainda mais presentes nos discursos dos chefes de Estado de esquerda. Essa interpretação se confirma quando se analisam os discursos sobre identidade regional no âmbito da Unasul (Meunier e Medeiros, 2013). A identidade compartilhada pelos países da região, baseada em valores e em uma história comuns, não se reflete nos acordos e políticas regionais concretas com a mesma intensidade que possui nas declarações das autoridades, pelo que a legitimidade das instituições regionais pode ser buscada em elementos externos, como no espelhamento em relação à União Europeia (Medeiros, Meunier e Cockles, 2015).

A essas debilidades, que restringem as possibilidades de uma efetiva liderança brasileira, soma-se outra deficiência das organizações regionais na América Latina: não ter aumentado significativamente os níveis de participação social e diálogo com a sociedade civil. O reforço dos aspectos políticos do regionalismo na década de 2000 incentivou o papel de atores tradicionais, como governos e partidos, mas deixou de incluir de modo substancial atores sociais que, em alguns casos, conformam redes regionais há várias décadas e já foram os responsáveis pela condução de agendas anti-hegemônicas (Serbin, 2013: 302). A abordagem centrada exclusivamente no Estado, e mais ainda nos poderes executivos, pode ocasionar políticas de cima para baixo mesmo em temas de grande mobilização e 
interesse, como políticas sociais ou ambientais. As práticas da diplomacia parlamentar (Costa, Dri e Stavridis, 2013), da diplomacia federativa (Medeiros e Saraiva, 2009; Botto, 2013) e da diplomacia civil (Sanchez, 2004; Barros, 2011) são dificilmente reconhecidas pelos ministérios de relações exteriores, que ainda são os atores centrais e quase exclusivos dos blocos regionais. São inúmeras as iniciativas de deputados, senadores, prefeitos, vereadores, organizações militantes ou associações profissionais, entre outros atores, para a gestão de temas transnacionais, mas essas ações encontram grande resistência nas burocracias que gerem as instituições regionais. Assim, persiste o quadro geral latino-americano de baixa capacidade de influência dos movimentos sociais nas políticas externas (Malamud, 2016).

O carisma e a popularidade de líderes como Lula e Néstor Kirchner conseguiram contornar essas evidências durante algum tempo e manter em um nível bastante positivo as relações regionais, mas o personalismo não é suficiente na criação de dinâmicas institucionais duradouras. Sem a implementação de políticas compartilhadas no âmbito das organizações, seria cada vez mais difícil para o Brasil manter a retórica da prioridade regional. É interessante notar que os limites da integração não dependem exclusivamente da agência dos tomadores de decisão brasileiros, mas podem também ter causas sistêmicas. É possível que o crescimento econômico e a visibilidade internacional das potências regionais estejam conduzindo um processo de multipolaridade centrífuga, que desestimula a integração regional enquanto reforça os laços extra-regionais entre os países emergentes (Garzón, 2015). Por outro lado, a situação de subdesenvolvimento econômico da América Latina pode também influenciar na difícil manutenção dos compromissos regionais. A dependência externa, as incertezas financeiras e as estratégias das grandes corporações multinacionais parecem determinar as crises do regionalismo latino-americano tanto quanto fatores endógenos (Botto, 2017).

Se considerados seriamente, os fatores exógenos podem questionar a suficiência das tentativas apresentadas até aqui para a caracterização do regionalismo latino-americano nos anos 2000. Todos esses recortes analíticos apreendem aspectos essenciais da realidade política latino-americana e explicam em grande medida o modo de funcionamento e as razões para a continuidade dos projetos regionais, além do tipo de comportamento avançado pelo Brasil. Os estudos argumentam que, devido ao baixo grau de identidade compartilhada, o Brasil não é considerado líder nato da região. Assim, instrumentaliza o regionalismo buscando essa liderança e também a manutenção de uma margem importante de autonomia. O regionalismo também é reativo contra ações externas indesejáveis, 
formal por consistir em um valor em si mesmo, declaratório considerando a dose de retórica discursiva a ele associada, e centralizado pelo fato de que as decisões precisam da chancela dos ministérios de relações exteriores. Essa tipologia é válida e pertinente, mas pode não ser suficiente.

Esse artigo pretende contribuir para o debate sobre a caracterização do regionalismo latino-americano e sobre a atuação regional do Brasil a partir do ponto de vista da deliberação. Desde essa perspectiva, as instituições regionais parecem ter gerado uma dinâmica de debates relevante na arena política. Os números da cooperação setorial no âmbito dos blocos regionais, oferecidos a seguir, demonstram que as negociações foram contínuas e intensificadas nos anos 2000, o que favorece a formação de canais de diálogo estáveis entre os vizinhos nos mais variados temas da atuação estatal. Ou seja, se as práticas incluem o regionalismo instrumental, podem não se restringir a ele. Na sequência, apresenta-se um panorama quantitativo das normas aprovadas no Mercosul, na Unasul e na CELAC e uma análise qualitativa de situações representativas que ilustram o papel desempenhado pelo Brasil em seu entorno regional.

\section{Os conteúdos do regionalismo deliberativo e instrumental}

Esta seção objetiva apresentar um quadro exaustivo e sistematizado dos temas tratados nas instâncias decisórias do Mercosul, Unasul e CELAC desde suas respectivas origens até o final de 2015. Esses três organismos foram escolhidos por contarem com a participação brasileira, cuja retórica referente à integração regional pretende-se verificar nesse estudo. A codificação temática reflete a ênfase dada pelas próprias instituições a cada setor. Uma área similar entre todas é o rótulo "institucional”, que se refere a atos que regulam o funcionamento interno das organizações. Não se indica aqui o nível de implementação de cada normativa, mas apenas a entrada de cada assunto na agenda regional. Assume-se que a simples inclusão de certos tópicos na pauta das unidades decisórias dos blocos latino-americanos demonstra algum interesse no seu tratamento regional. Oferece-se um panorama das ideias ou dos projetos que foram cogitados nos mais altos escalões políticos de cada organização, e que tinham, portanto, potencial de tornarem-se políticas regionais. Após o mapeamento, os temas mais recorrentes em cada organização são objeto de análise qualitativa. Não se trata aqui de estudos de caso, que exigiriam outros espaços, mas sim de exemplos que revelam a atuação brasileira na região e o caráter deliberativo-instrumental do regionalismo que vem sendo construído. 
O Mercosul teve seu ato constitutivo em 1991, calcado em importantes iniciativas anteriores como a Associação Latino-americana de Livre Comércio de 1960, a Associação Latino-americana de Integração de 1980, a aproximação energética entre os países do Rio da Prata nos anos 1970 e os acordos de cooperação Brasil-Argentina dos anos 1980. Concebido para fortalecer os regimes democráticos e a inserção internacional dos países do Cone Sul (Seitenfus, 1989; Medeiros, 2000), além de estimular o livre-comércio por meio da construção de um mercado comum (Gardini, 2007), o Mercosul está entre as iniciativas mais ambiciosas de integração regional na América Latina. Além dos quatro sóciosfundadores, o Mercosul promoveu a adesão da Venezuela a partir de 2006, e sua posterior suspensão em 2017. Embora tenha dinamizado o comércio intra-regional, o Mercosul ainda não conseguiu alcançar seus objetivos de integração econômica (Vaillant, 2014). A partir de meados dos anos 2000, o bloco vem investindo em objetivos políticos e sociais, espelhados na criação de órgãos como o Parlamento do Mercosul em 2005, o Instituto Social do Mercosul em 2007 e o Instituto de Políticas Públicas em Direitos Humanos em 2009. Apesar dessas mudanças, os três únicos órgãos com poder decisório continuam os mesmos desde as origens do bloco e são formados majoritariamente por representantes dos ministérios de relações exteriores de cada país: Conselho Mercado Comum, Grupo Mercado Comum e Comissão de Comércio. A agenda com base nas normas aprovadas segue na tabela 1 e nos gráficos 1 e 2 . A tipologia condensa os atos desses três órgãos e faz referência à vocação principal da norma ressaltada em seu preâmbulo. 


\section{Revista SAAP $\cdot$ Vol. 14, № 1}

Tabela 1

Agenda Mercosul por período 1991-2015

\begin{tabular}{|c|c|c|c|}
\hline Tema/período & 1991-2002 & 2003-2015 & $\begin{array}{l}\text { Total de normas } \\
\text { por tema }\end{array}$ \\
\hline Livre comércio & 961 & 888 & 1849 \\
\hline Institucional & 149 & 239 & 388 \\
\hline Economia & 14 & 6 & 20 \\
\hline Educação & 16 & 25 & 41 \\
\hline Justiça e cooperação jurisdicional & 33 & 40 & 73 \\
\hline Relações internacionais do Mercosul & 31 & 112 & 143 \\
\hline Livre circulação de pessoas & 21 & 22 & 43 \\
\hline Trabalho e emprego & 9 & 12 & 21 \\
\hline Direitos humanos & 2 & 26 & 28 \\
\hline Agricultura & 2 & 10 & 12 \\
\hline Cultura & 4 & 17 & 21 \\
\hline Saúde & 26 & 72 & 98 \\
\hline Propriedade intelectual & 5 & 2 & 7 \\
\hline Cooperação policial e segurança & 42 & 18 & 60 \\
\hline Indústria & 7 & 18 & 25 \\
\hline Energia & 5 & 4 & 9 \\
\hline Esportes & 0 & 2 & 2 \\
\hline Cooperativismo & 1 & 2 & 3 \\
\hline Turismo & 4 & 4 & 8 \\
\hline Meio ambiente & 7 & 19 & 26 \\
\hline Ciência e tecnologia & 3 & 8 & 11 \\
\hline Infraestrutura & 2 & 84 & 86 \\
\hline Comunicação & 32 & 10 & 42 \\
\hline Estados e municípios & 2 & 5 & 7 \\
\hline Gênero & 4 & 5 & 9 \\
\hline Drogas & 2 & 1 & 3 \\
\hline Inclusão social & 1 & 23 & 24 \\
\hline Democracia & 0 & 12 & 12 \\
\hline Terrorismo internacional & 0 & 1 & 1 \\
\hline Norma com conteúdo reservado & 7 & 0 & 7 \\
\hline Total por período & 1392 & 1687 & 3079 \\
\hline
\end{tabular}

Fonte: elaboração dos autores com base nas decisões do Conselho Mercado Comum, resoluções do Grupo Mercado Comum e disposições da Comissão de Comércio do Mercosul. Dados disponíveis no site mercosur.int. 


\section{Gráfico 1 \\ Agenda Mercosul consolidada 1991-2002}

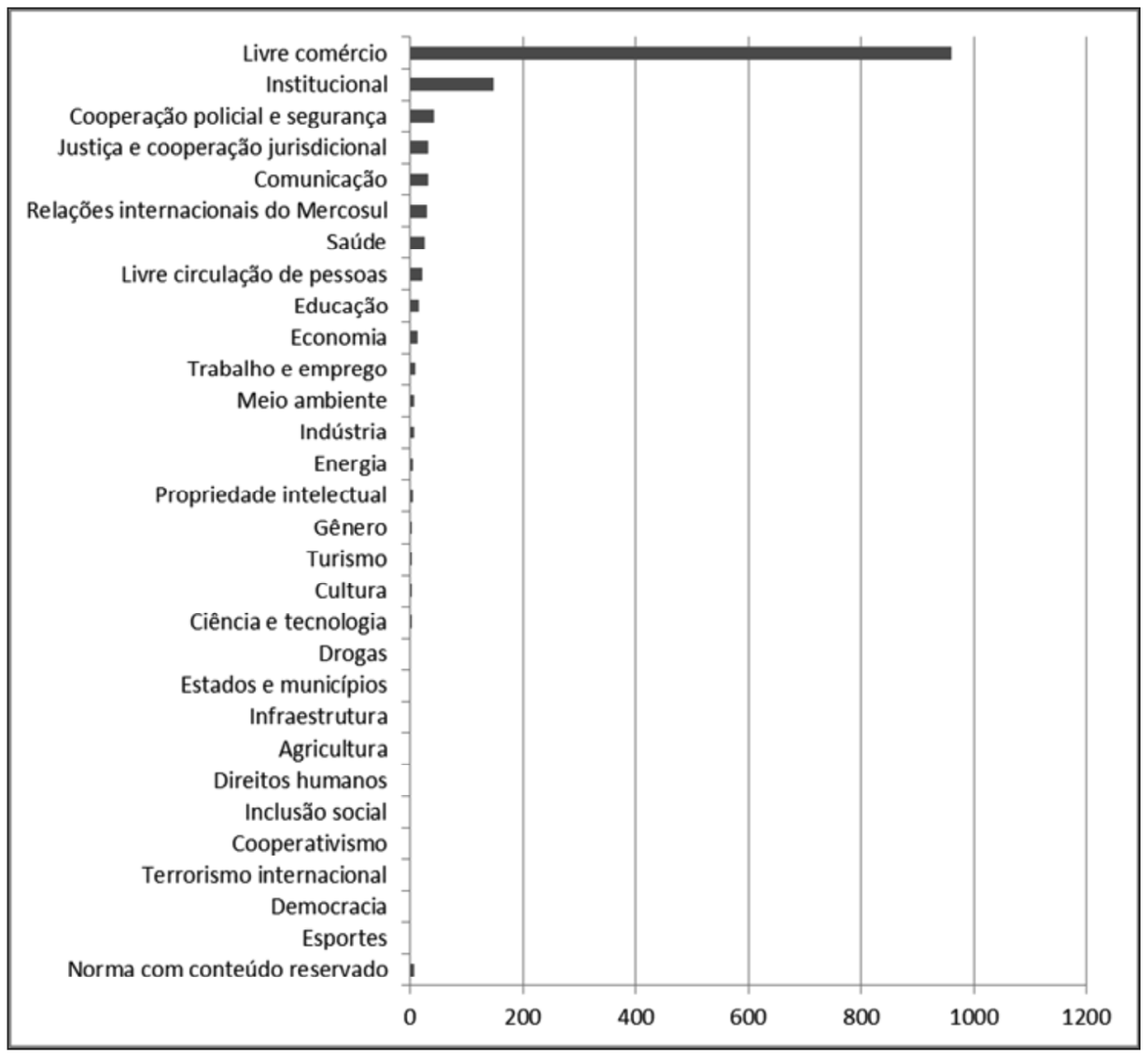

Fonte: elaboração dos autores com base nas decisões do Conselho Mercado Comum, resoluções do Grupo Mercado Comum e disposições da Comissão de Comércio do Mercosul. Dados disponíveis no site mercosur.int.

Observação: estão zerados os itens Esportes, Democracia e Terrorismo Internacional. 
Gráfico 2

Agenda Mercosul consolidada 2003-2015

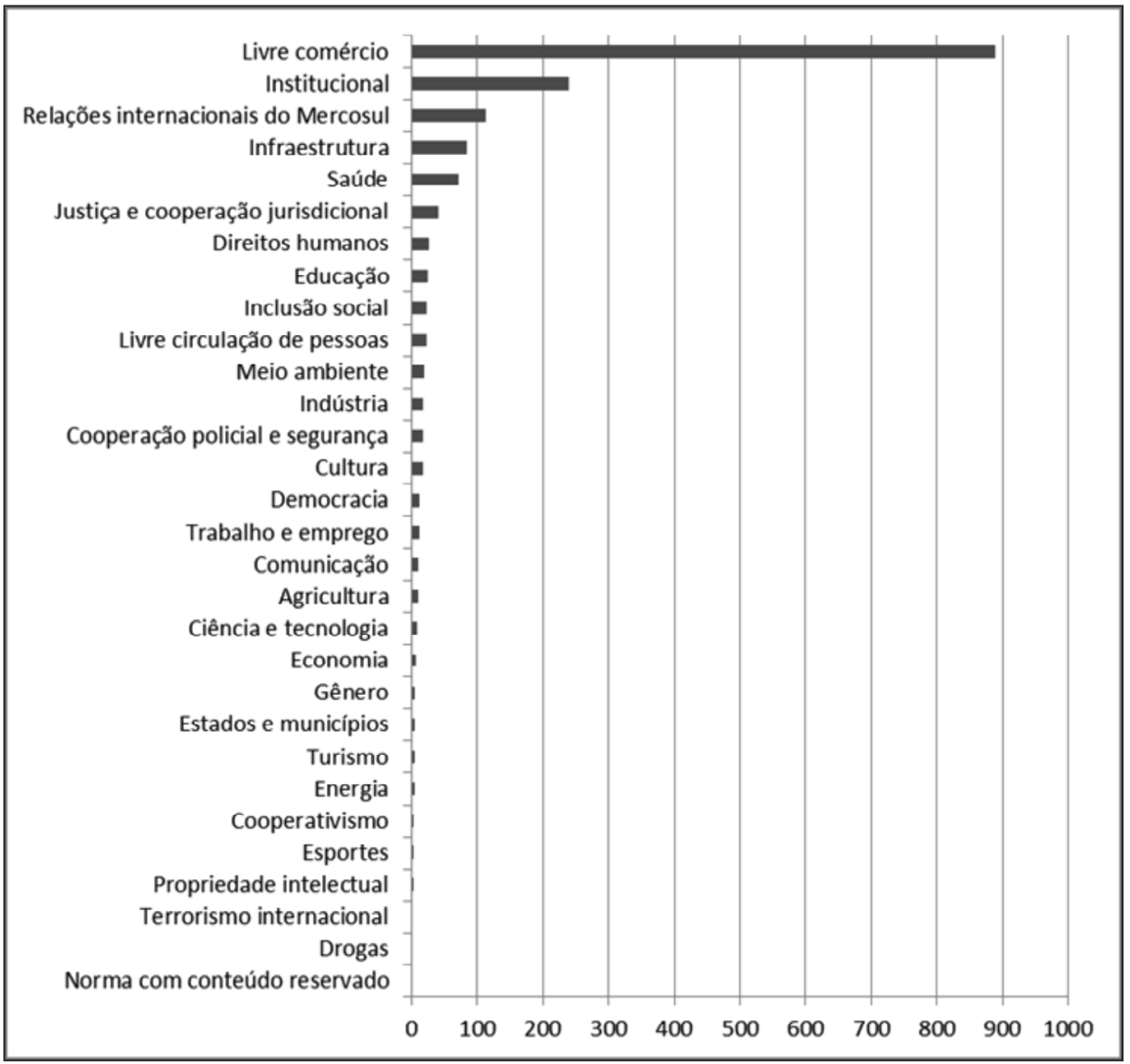

Fonte: elaboração dos autores com base nas decisões do Conselho Mercado Comum, resoluções do Grupo Mercado Comum e disposições da Comissão de Comércio do Mercosul. Dados disponíveis no site mercosur.int.

Observação: está zerado apenas o item Norma com conteúdo reservado.

Em linhas gerais, o tema do livre comércio diz respeito aos atos vinculados à regulamentação (evolutiva ou regressiva) da liberalização comercial e de serviços, e à harmonização tarifária para constituição da união aduaneira. Os anos 1990 testemunharam o auge dos esforços pela liberalização, enquanto a partir de 2005 as normas dessa categoria mencionam mais a adequação de tarifas comuns a previsões de abastecimento e necessidades 
nacionais. Justiça refere-se à cooperação jurisdicional e ao desenvolvimento do sistema de solução de controvérsias no bloco. Percebe-se que o foco na primeira década do bloco foi a liberalização comercial e, em menor medida, a cooperação policial para o combate a ilícitos. As dificuldades de implementação dessas decisões ficam claras nas próprias normas, que se repetem anualmente e cujos textos buscam orientar os órgãos nacionais sobre como agir face à nova normativa regional. A partir dos nos 2000, temas como inclusão social, democracia e cooperativismo entraram na agenda do bloco. O tema da agricultura, a partir de 2005, faz referência sobretudo a encontros sobre agricultura familiar, e as normas sobre cultura no mesmo período são majoritariamente relacionadas ao cinema e co-produções cinematográficas. A partir de 2010, a temática dos direitos humanos começa a incluir discussões sobre povos indígenas e afrodescendentes.

Uma análise mais específica dos temas numericamente mais representativos, e com maior variação de uma década à outra, inclui as relações internacionais do Mercosul, a saúde e a infraestrutura. No caso das relações internacionais, estão incluídos acordos de liberalização comercial, cooperação e diálogo político com países ou organizações internacionais, além de normas para associação ou adesão ao bloco e normas que definem as prioridades em termos de cooperação financeira e técnica recebida. A partir dos anos 2000, o número de acordos com esses conteúdos aumentou consideravelmente, mostrando o interesse crescente no Mercosul por parte de outros Estados e organizações, ademais de revelar o interesse dos membros em melhorar e diversificar sua inserção internacional, considerando a pluralidade dos parceiros signatários. Aqui se infere a criação de uma dinâmica de diálogo entre as diplomacias dos países do Mercosul sobre seus relacionamentos externos, embora o Brasil tenha adotado concomitantemente uma estratégia de inserção internacional unilateral.

Os debates sobre saúde estão presentes no Mercosul desde sua fundação, devido à necessidade de eliminar obstáculos técnicos para a livre circulação de alimentos e fármacos, além de estabelecer padrões regionais para a agropecuária e a indústria. Gradualmente, o grupo de trabalho encarregado desse tema passou a tratar de pautas mais amplas do que o livre-comércio, como cooperação técnica em saúde, aquisição de medicamentos e vigilância epidemiológica (Queiroz e Giovanella, 2011: 185). Esses temas ganharam espaço considerável a partir dos anos 2000, estruturando uma importante arena de deliberação transnacional envolvendo profissionais de saúde dos países do bloco. Essa dinâmica foi transportada para a nascente Unasul em 2008, cujo Conselho de Saúde é considerado relevante espaço de prática política (Riggirozzi, 2015a); de solidariedade, de prática coletiva e de luta por soberania e autonomia (Herrero, 2017); de reivindicação de direitos e justiça social e de construção de caminhos alternativos para a saúde global (Riggirozzi, 2015b). 
As iniciativas brasileiras em saúde no plano internacional devem-se em grande parte à estruturação desse serviço público e universal a partir da redemocratização, o que gerou uma burocracia militante e organizada na defesa das pautas sanitárias. O empreendedorismo dos atores brasileiros nesse tema, no Mercosul e na Unasul, levou à construção de espaços regionais de comunicação e de troca de experiências que buscam garantir e reforçar o acesso à saúde nos Estados-membros (inclusive dentro do próprio Brasil). Um momento representativo desse processo foi a criação, em 2009, do Instituto Sul-americano de Governo em Saúde (ISAGS), com sede no Rio de Janeiro e a nomeação de diretor brasileiro a partir de iniciativa da Fundação Oswaldo Cruz, vinculada ao Ministério da Saúde. No entanto, apesar da estruturação de diálogos e práticas de extrema relevância, persistem dificuldades na cooperação regional em saúde, como a falta de harmonização das legislações nacionais e das bases de dados, a desigualdade no acesso à tecnologia, os obstáculos para o reconhecimento mútuo do exercício profissional e a falta de estrutura nas regiões de fronteira (Queiroz e Giovanella, 2011: 187), o que demonstra uma liderança brasileira mais focada na exportação das práticas domésticas do que na negociação e concertação regional.

No tocante à infraestrutura, a temática ganhou destaque a partir da criação do Fundo para a Convergência Estrutural do Mercosul (FOCEM) em 2005. No entanto, a Inciativa para Integração da Infraestrutura Regional Sul-Americana (IIRSA) já estava em andamento desde 2000, sendo posteriormente anexada à Unasul como um de seus principais eixos. Em ambos os casos, linhas orçamentárias específicas foram atribuídas a projetos de transporte, energia, comunicações, logística e urbanismo, e equipes de trabalho para gestão dos projetos foram montadas, gerando uma dinâmica transnacional de relevo nessas áreas. O Brasil participa como um dos financiadores centrais das iniciativas, considerando seu produto interno bruto relativo na América do Sul. No entanto, sobretudo no caso do Mercosul, o orçamento do FOCEM é bastante restrito e o Brasil apenas acatou a criação do órgão, que era demanda antiga dos sócios menos populosos, como moeda de troca para a criação do Parlamento do Mercosul (Dri, 2014: 207).

A Unasul, por sua vez, foi oficializada em $2008 \mathrm{com}$ a assinatura de seu tratado constitutivo, e é composta pelos 12 estados sul-americanos. Trata-se da cristalização de um novo momento no regionalismo latino-americano, vinculado à chegada das forças de esquerda ao poder. O período entre o início da década de 2000 e meados da década 2010 é usualmente caracterizado como a quarta onda regional na América Latina, marcada pela "integração póscomércio" (Dabène, 2016b: 32), como um momento de regionalismo pósliberal (Veiga e Rios, 2007; Sanahuja, 2008), maximalista (Briceño-Ruiz, 2010), estratégico (Bizzozero, 2011), ou pós-hegemônico (Tussie e Riggirozzi, 2012). 
Sua origem está vinculada à iniciativa brasileira de formação da Comunidade Sul-americana de Nações (CASA), baseada na aproximação entre o Mercosul e a Comunidade Andina a partir de componentes comerciais e políticos. No decorrer das negociações, as críticas venezuelanas foram incorporadas no sentido da inclusão de temas sociais, como cidadania e identidade, o que refletia a disputa em curso entre Brasil e Venezuela pela liderança regional (BriceñoRuiz, 2010). Seus atos normativos principais, segundo o Regulamento Geral da Unasul, são as decisões emanadas das cúpulas presidenciais, as resoluções das reuniões de ministros e as disposições operacionais do conselho de delegados (tabela 2 e gráfico 3). Assim como no Mercosul, os conselhos setoriais, criados gradualmente a partir de 2008, podem apresentar propostas aos presidentes, mas por intermédio do conselho de delegados, que é formado por diplomatas representando cada um dos Estados-membros.

\section{Tabela 2}

\section{Agenda Unasul anual 2008-2015}

\begin{tabular}{|c|c|c|c|c|c|c|c|c|c|}
\hline Tema/ano & $\mathbf{2 0 0 8}$ & $\mathbf{2 0 0 9}$ & $\mathbf{2 0 1 0}$ & $\mathbf{2 0 1 1}$ & $\mathbf{2 0 1 2}$ & $\mathbf{2 0 1 3}$ & $\mathbf{2 0 1 4}$ & $\mathbf{2 0 1 5}$ & $\begin{array}{c}\text { Total de atos } \\
\text { por tema }\end{array}$ \\
\hline Institucional & 4 & & 6 & 4 & 17 & 12 & 6 & 12 & 61 \\
\hline Bolívia & 1 & & & & & & & & 1 \\
\hline Paraguai & & & & & 2 & & & & 2 \\
\hline Venezuela & & & & & & & 1 & & 1 \\
\hline Haiti & & & 2 & & 1 & 2 & 1 & & 6 \\
\hline Economia e finanças & 2 & & 3 & & 1 & & & & 6 \\
\hline Energia & 1 & & 1 & & 1 & & & & 3 \\
\hline Segurança e defesa & 1 & 3 & 1 & & 8 & 1 & 1 & & 15 \\
\hline Infraestrutura & & 1 & & & 7 & & & 2 & 10 \\
\hline Saúde & 1 & & & & 8 & & 1 & & 10 \\
\hline Drogas & & 1 & 1 & & 2 & & & 1 & 5 \\
\hline Cultura & & 1 & 1 & & 2 & & & & 4 \\
\hline Ciência e tecnologia & & 1 & 1 & & 2 & 1 & & & 5 \\
\hline Educação & 1 & 1 & 1 & & 2 & 1 & 1 & & 7 \\
\hline Democracia & & & & 1 & 4 & 3 & 5 & 6 & 19 \\
\hline Migração & & & & & 3 & & 1 & & 4 \\
\hline Inclusão social & 2 & 1 & & & 4 & & & & 7 \\
\hline Direitos humanos & & & & & & 1 & & & 1 \\
\hline Cooperação sul-sul & & & & & & & & 1 & 1 \\
\hline Total de atos por ano & 13 & 9 & 17 & 5 & 64 & 21 & 17 & 22 & \\
\hline & & & & & & \\
\hline
\end{tabular}

Fonte: elaboração dos autores com base nas decisões, resoluções e disposições dos órgãos decisórios da Unasul. Dados disponíveis nos sites docs.unasur.org e itamaraty.gov.br/politica-externa/integracao-regional/13221-documentos-da-uniao-denacoes-sul-americanas. 
Gráfico 3

Agenda Unasul consolidada 2008-2015

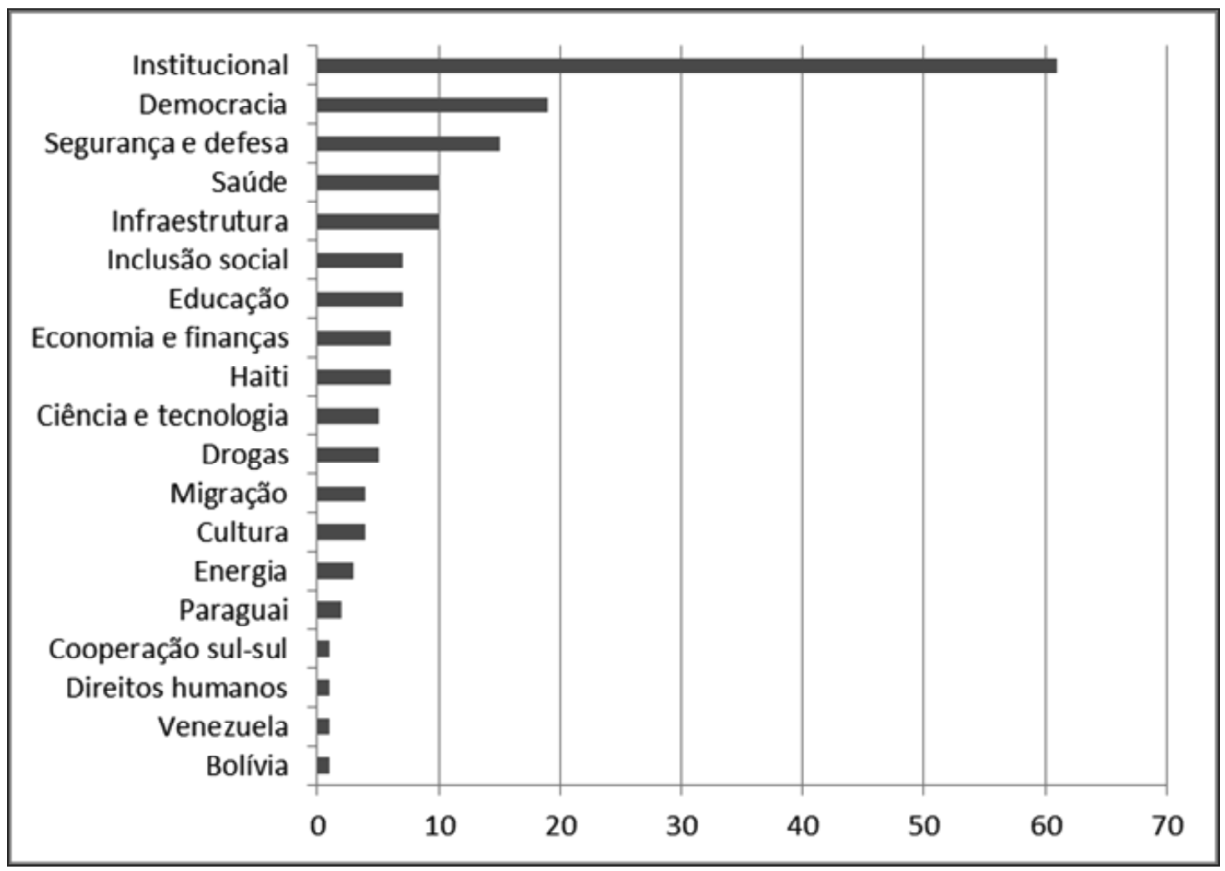

Fonte: elaboração dos autores com base nas decisões, resoluções e disposições dos órgãos decisórios da Unasul. Dados disponíveis nos sites docs.unasur.org e itamaraty.gov.br/politica-externa/integracao-regional/13221-documentos-da-uniao-denacoes-sul-americanas.

Panoramicamente, a normativa institucional refere-se à gestão do orçamento e à análise de projetos candidatos a financiamento pelo fundo comum, o que demonstra maior institucionalidade do que a CELAC, conforme se verá diante. Mesmo assim, o espaço desse tópico não se compara à tentativa de arquitetura institucional do Mercosul e denota um novo modelo de organização regional, mais próximo das coalizões ou redes do que das organizações internacionais clássicas. Muitas decisões temáticas são referentes à criação dos conselhos setoriais e a grupos de trabalho que se reúnem periodicamente, ou seja, o tema da norma tem continuidade nas discussões setoriais. Em termos específicos, quantitativamente percebe-se a continuidade dos temas de saúde e infraestrutura, já destacados no último período do Mercosul, e a importância de novas pautas como democracia e defesa. Nesse último 
ponto, nota-se uma mudança de foco da cooperação policial, presente nos primeiros anos do Mercosul, para a ênfase em defesa na estruturação da Unasul. Embora tenha provocado um reforço do diálogo e um espaço de busca de autonomia com relação aos Estados Unidos, o Conselho Sul-Americano de Defesa serviu mais aos propósitos do Brasil de tornar-se um influente ator global e de consolidar sua influência regional, do que à criação de confianças mútuas e estratégias conjuntas de segurança e defesa (Vaz, Fuccile e Rezende, 2017). Por outro lado, os escassos investimentos brasileiros na área da defesa tornam necessária essa arena de deliberação, mostrando que o Brasil também depende da região para a construção de sua própria autonomia.

A pauta da democracia demonstra a tentativa de centralização de um espaço de deliberação política sul-americana já existente, mas de modo difuso. As missões de acompanhamento eleitoral passaram, em alguns casos, a ser coordenadas no âmbito regional, e as crises políticas nacionais ganharam um novo fórum para seguimento e avaliação. Isso fica claro também nas normas destinadas a situações nacionais específicas (notadamente Haiti, Venezuela, Bolívia e Paraguai). A autonomia de um espaço sem a participação dos Estados Unidos reforça a vocação da Unasul como arena de discussão política multilateral para temas sensíveis e centrais para a região, embora as ações de mediação desempenhadas tenham sido incipientes e comparáveis a uma diplomacia preventiva dependente de secretários-gerais de grande peso político (Borda, 2012: 20).

A criação da CELAC foi anunciada durante reunião de Estados latino-americanos no México, em 2010, e oficializada na reunião de Caracas de 2011. Duas reuniões anteriores de concertação e diálogo, realizadas em 2008 e 2009 no Brasil e na Jamaica, respectivamente, lançaram as bases imediatas da nova organização. Suas origens estão vinculadas ao Grupo do Rio e aos esforços coletivos pela renegociação da dívida externa dos Estados latino-americanos nos anos 1980. Nas declarações finais das primeiras reuniões, ressalta-se o objetivo de fortalecer a cooperação em áreas de interesse comum com base nos princípios de flexibilidade, diversidade, complementariedade de ações e participação voluntária nas iniciativas. A organização tem como membros todos os 33 Estados latino-americanos e caribenhos e realiza uma cúpula de presidentes por ano desde 2013. Os documentos emanados dessas cúpulas, bem como das reuniões fundacionais, são apresentados na tabela 3 e no gráfico 4. Essa sistematização inclui as declarações e comunicados de chefes de Estado e de governo, bem como reuniões e seminários setoriais anunciados nos planos de trabalho anuais. Os documentos das reuniões de ministros de relações exteriores e das reuniões dos coordenadores nacionais não foram contabilizados porque não estão disponíveis publicamente. 
Revista SAAP $\cdot$ Vol. 14, № 1

Tabela 3

Agenda CELAC anual 2008-2015

\begin{tabular}{|c|c|c|c|c|c|c|c|c|}
\hline Tema/ano & 2008 & 2009 & 2010 & 2011 & 2013 & 2014 & 2015 & $\begin{array}{c}\text { Total de atos } \\
\text { por tema }\end{array}$ \\
\hline Institucional & 1 & 1 & 1 & 2 & 3 & 4 & 3 & 15 \\
\hline Cuba & & & 1 & 1 & 1 & 1 & 1 & 5 \\
\hline Equador & & & 1 & & & & & 1 \\
\hline Haiti & & & 1 & 1 & 1 & & 1 & 4 \\
\hline Guatemala & & & 1 & & & & & 1 \\
\hline Brasil & & & & & 1 & & & 1 \\
\hline Paraguai & & & & 1 & & 1 & 1 & 3 \\
\hline Colômbia & & & & & & 1 & 1 & 2 \\
\hline Venezuela & & & & & & & 1 & 1 \\
\hline Malvinas & & & 2 & 1 & 1 & 2 & 1 & 7 \\
\hline China & & & & & & 1 & & 1 \\
\hline Emprego & & & & 1 & & & 1 & 2 \\
\hline $\begin{array}{l}\text { Subdesenvolvimento } \\
\text { econômico }\end{array}$ & & 1 & & 1 & & 2 & 6 & 10 \\
\hline $\begin{array}{l}\text { Crise financeira } \\
\text { internacional }\end{array}$ & & 1 & & 1 & 1 & 1 & 1 & 5 \\
\hline Industrialização & & & & & 1 & 1 & 1 & 3 \\
\hline Infraestrutura & & 1 & & 1 & 1 & 1 & 1 & 5 \\
\hline Energia & & 1 & & 2 & 1 & 1 & 1 & 6 \\
\hline Segurança e defesa & & & & 3 & 1 & 5 & 7 & 16 \\
\hline Drogas & & & & 1 & 1 & 2 & 2 & 6 \\
\hline Democracia & & & & 1 & & 1 & 1 & 3 \\
\hline Corrupção & & & & & & 1 & 1 & 2 \\
\hline Direitos humanos & & & & & & 6 & 4 & 10 \\
\hline Migração & & & 1 & 2 & 1 & 2 & 1 & 7 \\
\hline Cultura & & & & 3 & 4 & 4 & 2 & 13 \\
\hline Meio ambiente & & 1 & 1 & 3 & 2 & 5 & 5 & 17 \\
\hline Educação & & & & & 1 & 1 & 1 & 3 \\
\hline Ciência e tecnologia & & & & & 1 & 1 & 1 & 3 \\
\hline Agricultura familiar & & & & & 1 & 1 & 1 & 3 \\
\hline Segurança alimentar & & 1 & & 2 & & 1 & 1 & 5 \\
\hline Total de atos por ano & 1 & 7 & 9 & 27 & 23 & 46 & 47 & \\
\hline
\end{tabular}

Fonte: elaboração dos autores com base nas declarações, comunicados e planos de ação das reuniões de cúpula da CELAC. Dados disponíveis nos sites celac.gob.ve, celac.cubaminrex.cu, sela.org/celac e itamaraty.gov.br/ficha-pais/13223-documentoscomunidade-de-estados-latino-americanos-e-caribenhos. 


\section{Gráfico 4 \\ Agenda CELAC consolidada 2008-2015}

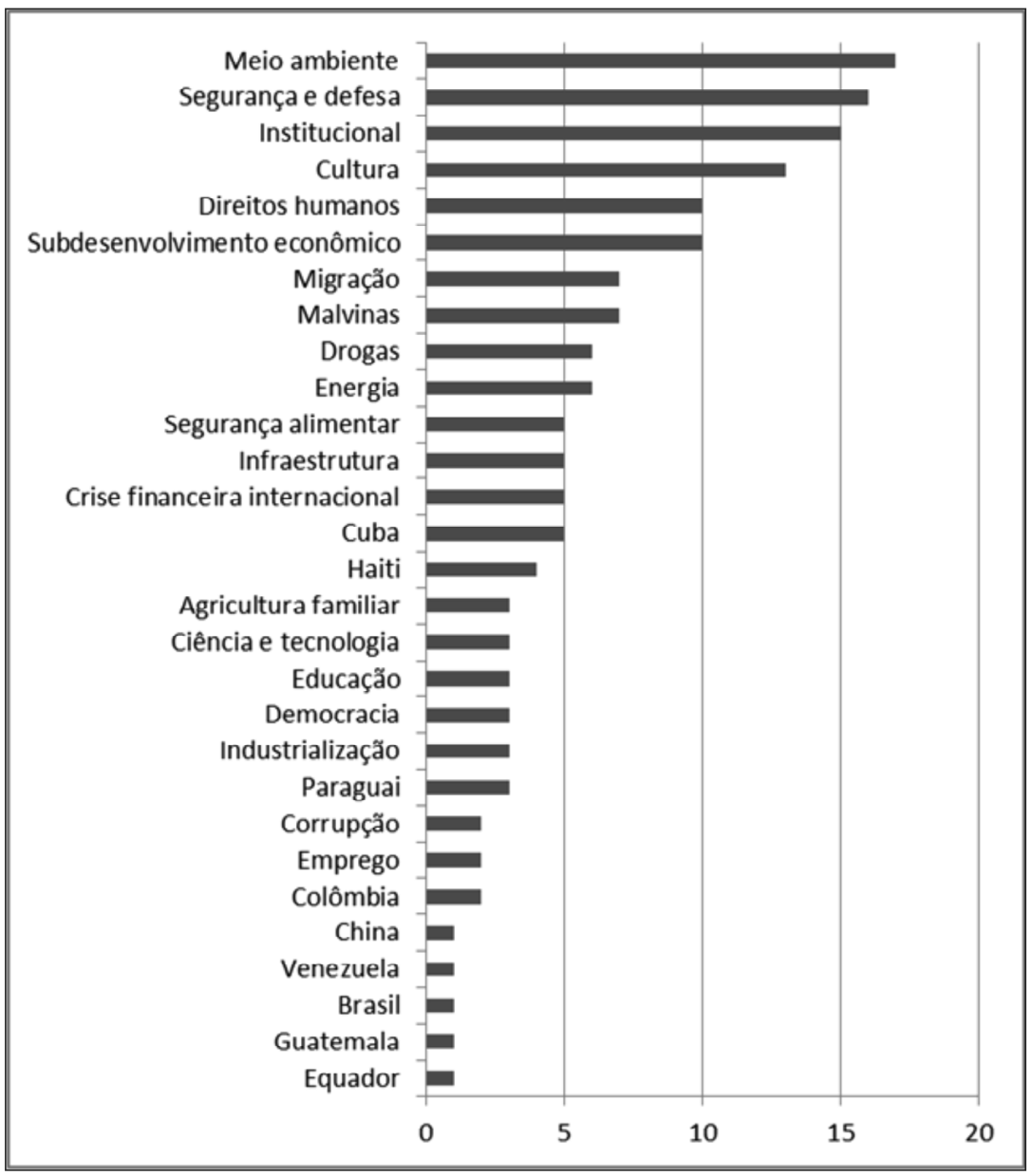

Fonte: elaboração dos autores com base nas declarações, comunicados e planos de ação das reuniões de cúpula da CELAC. Dados disponíveis nos sites celac.gob.ve, celac.cubaminrex.cu, sela.org/celac e itamaraty.gov.br/ficha-pais/13223-documentoscomunidade-de-estados-latino-americanos-e-caribenhos. 
Três elementos merecem destaque na agenda da CELAC. Em primeiro lugar, a importância do tópico segurança e defesa, que dá seguimento à pauta da Unasul. Nesse item, estão agrupadas principalmente declarações sobre o tráfico de armas, cyber segurança e o terrorismo, ponto no qual a organização faz referências indiretas ao terrorismo de Estado praticado por países ocidentais. Um segundo elemento de destaque é o espaço para novos temas trazidos pelos países da América Central e do Caribe. Em direitos humanos, por exemplo, as menções à memória sobre o passado escravocrata da região e a proteção dos povos indígenas são recorrentes, e mais recentemente entraram temas como gênero e racismo. De modo similar, o tema da cultura ressalta a importância de práticas e ritos indígenas ancestrais e patrimônios naturais para a identidade da região. No item meio ambiente, a necessidade de organização regional frente às catástrofes naturais, frequentes sobretudo nos países caribenhos, é mencionada, assim como preocupações com a mudança climática. Em terceiro lugar, surgem como relevantes as preocupações com particularidades e crises nacionais, o que reflete a continuidade, agora com novas proporções, do fórum de diálogo político estabelecido na Unasul. Nas sínteses das reuniões, a CELAC insiste na necessidade da superação do subdesenvolvimento na região, concentrando o foco das cúpulas em tópicos como o combate à fome e à pobreza e a participação da América Latina e Caribe na construção da agenda internacional de desenvolvimento sustentável.

Brasil e México são apontados como os estados mais ativos no surgimento dessa nova organização (Rojas, 2010: 7), que é vista pelos mexicanos como complemento ou reação à iniciativa anterior sul-americana. Com efeito, a notícia da criação da Unasul havia sido recebida como um choque pela diplomacia mexicana, que a comparou a um tipo de doutrina Monroe tropical: "América do Sul para os brasileiros" (Covarrubias, 2016: 54). A CELAC representaria, assim, a afirmação mexicana e ilustraria a presença de ambos os líderes, Brasil e México, no diálogo regional. A orientação da agenda demonstra, de fato, a vocação da CELAC para a concertação de posições em esferas internacionais - especialmente no tocante ao desenvolvimentoe para a consolidação de um espaço político moderador sem a presença dos Estados Unidos — excluindo, portanto, a clivagem Norte-Sul—, na esteira do histórico de mediação de crises e tensões do Grupo do Rio (Rojas, 2012: 19). Isso pode ser observado pela presença, nas discussões, de temas como a questão das Malvinas, o embargo cubano e as crises domésticas colombiana, haitiana e venezuelana, e também pela preocupação expressa nas declarações em fomentar a cooperação sul-sul. Pode-se afirmar que os esforços regionais nos anos 2000 resultaram, assim, na criação de instâncias deliberativas especializadas em temas de interesse para a região. Esses espa- 


\section{Clarissa Franzoi Dri y Tiago Mocellin Pittas}

ços deliberativos não apenas encerram um grande potencial de diálogo e mediação política, como já promovem a aproximação e o conhecimento mútuo entre países vizinhos. Podem ser considerados como aprofundamento e alargamento do processo de regionalização na América Latina iniciado nos anos 1960.

Voltando ao comportamento brasileiro, percebe-se, paralelamente aos espaços de deliberação mencionados acima, certa instrumentalização dessas três instâncias regionais por parte do Brasil em prol de objetivos outros que não apenas a integração regional, conforme apontado por parte da literatura revisada na primeira parte do texto. Essa inferência deriva das situações analisadas até aqui, especialmente dos temas de mais destaque na agenda da Unasul. A priorização de tópicos como saúde, defesa e democracia demonstra o ativismo de atores brasileiros na elevação de seus interesses ao plano regional. Nesse processo, ao mesmo tempo em que o Brasil facilita arenas de deliberação, ele também avança suas ideias prévias sobre cada um desses setores, oferecendo e financiando treinamentos, compartilhando experiências brasileiras exitosas e buscando mediar conflitos políticos. O Brasil coloca-se, nesses temas, mais como provedor do que receptor de soluções, o que corresponde ao comportamento de quem busca liderança. A própria formação da Unasul e da CELAC contou com grande empreendedorismo da parte do Brasil, o que pode advir de um desejo de alargar sua zona de influência e estabelecer canais de diálogo permanente para além dos países do Mercosul.

A instrumentalização das arenas regionais revela-se também em casos ausentes ou menos relevantes no panorama quantitativo das normas. Por exemplo, os direitos das mulheres e dos migrantes foram tópicos avançados fortemente pela diplomacia argentina nos anos 2000, assim como as questões de ciência e tecnologia vinculadas ao desenvolvimento produtivo no caso do Uruguai. Nem todos os projetos propostos por esses países, baseados em experiências ou necessidades argentinas e uruguaias, foram tratados com centralidade no âmbito no Mercosul ou receberam continuidade por parte de atores brasileiros. Sobre as questões de gênero, a Argentina propôs, a partir de 2013, o foco no empoderamento econômico das mulheres, ao invés de restringir as discussões no Mercosul ao combate à violência de gênero. Os projetos argentinos não foram considerados como fonte de novos acordos regionais no setor (Palma, 2016). Nos temas migratórios, a Argentina foi pioneira na região com a adoção, em 2003, de uma nova legislação garantista dos direitos dos migrantes. Iniciou-se um ativismo argentino, por um lado, pela adoção plena da livre-circulação de pessoas no Mercosul, e, por outro lado, pela harmonização das legislações migratórias nacionais. O primeiro objetivo foi atingido com o Acordo de Residência do 
Mercosul, que entrou em vigor em 2009. Sobre as mudanças legislativas, apenas o Uruguai emulou a proposta argentina, sendo que o Brasil tardou nas discussões sobre a reforma normativa e apenas promulgou sua nova Lei de Migrações em 2017, sem que tenha havido grande interesse, por parte dos responsáveis brasileiros, sobre o modelo argentino (Culpi e Pereira, 2016). No entanto, o Brasil participou ativamente das discussões desses fóruns setoriais e cooperou com os debates em andamento. A abertura para essas arenas de deliberação provocou o reforço do regime regional de proteção aos migrantes e refugiados, com o já citado Acordo de Residência e a Declaração de Princípios do Mercosul sobre Proteção Internacional dos Refugiados, assinada em 2012.

Esses casos merecem exame mais detalhado em futuros estudos, que identifiquem principalmente os atores centrais em cada etapa dos processos. Com os dados atuais, pode-se concluir por um duplo resultado das práticas regionais nos anos 2000. De um lado, tem-se a instrumentalização do regionalismo em prol da liderança do Brasil e de sua imagem internacional presente nas políticas que foram pautadas pelos representantes brasileiros nas três organizações. De outro lado, ao mesmo tempo verificam-se esforços coletivos, inclusive da parte brasileira, pela formação de arenas de deliberação entre vizinhos, dispostos a criar condições para solucionar conflitos, mediar crises e mesmo compartilhar planos de desenvolvimento sem influência externa direta. Os limites desses resultados relacionam-se com o reconhecimento restrito e parcial da legitimidade brasileira para representação internacional da região, e com as incertezas atuais sobre a permanência dos espaços deliberativos criados. Um maior fortalecimento da cooperação regional, por meio da implementação de políticas efetivamente compartilhadas, baseadas em altos níveis de complacência por parte do Brasil e dos outros Estados da região, teria construído cenários diferentes para a liderança brasileira e para a estabilidade do diálogo e da integração regional?

\section{Conclusão}

Este artigo buscou traçar um balanço das iniciativas dos governos progressistas para a América Latina, com especial ênfase na avaliação da atuação brasileira. Buscou também mapear e interpretar a complementaridade ou a concorrência de pautas temáticas entre o Mercosul, Unasul e CELAC. Para isso, na primeira parte foi apresentada uma revisão da literatura especializada em regionalismo e suas visões sobre o potencial e as características da liderança brasileira. Calcados entre a apologia da solidariedade regional brasileira e as críticas ao seu frágil e autoproclamado status de líder regional, os 
argumentos trouxeram a necessidade de explicar de modo mais concreto quais foram os pontos fortes e as limitações do Brasil em sua política externa para a região. Assim, a segunda parte apresentou dados sistemáticos sobre as agendas dos órgãos decisórios de três organizações regionais com participação brasileira, com base na premissa de que a compreensão das possibilidades de construção de um regionalismo na heterogeneidade (Lima, 2013: 177) requer análise informada empiricamente (Legler, 2013: 342). A análise qualitativa dos acordos aprovados no Mercosul, na Unasul e na CELAC permitiu verificar algumas tendências.

Entre as décadas de 2000 e 2010, houve de fato uma aproximação entre os Estados latino-americanos para além dos âmbitos econômico e comercial, mas o Brasil não demonstrou o mesmo comprometimento que requeria de seus vizinhos. Os assuntos relevantes aos atores brasileiros tornaram-se as pautas regionais prioritárias, o que revela pouca abertura, por parte do governo, a temas mais caros a outros países. O governo e a diplomacia parecem ter trabalhado, na busca dos consensos, por liderança e estabilidade regional, mais do que por cooperação regional como os documentos oficiais anunciavam. A integração regional foi assim instrumentalizada com a finalidade de contribuir para a afirmação da liderança, e não evoluiu para a construção de políticas compartilhadas ou bens públicos regionais. Pouco se avançou nos níveis de regulação e redistribuição regional nos setores normatizados pelas organizações. Reforça essa interpretação o fato de que os temas que emergiram na categorização dos dados ressaltam certa complementaridade das organizações regionais, que retomam de modo diferenciado ou alargado temas já trabalhados em outras instituições. Nesse caso, tratou-se de expandir o escopo de alcance das pautas brasileiras e buscar apoio para novas práticas.

Por outro lado, a complementaridade aparece também no surgimento de novos temas conjunturais em cada organização. Isso revela um espaço para debate político sobre temas urgentes ou de interesse dos Estados, demonstrando uma vontade de concertação política e o reconhecimento dos vizinhos como parceiros relevantes para o diálogo multilateral e a inserção internacional. Ou seja, essas arenas foram tratadas como espaços deliberativos. Se a região América Latina está em formação, seus atores encontram-se na fase de conhecimento e reconhecimento, o que não se confunde com integração ou cooperação. No entanto, a deliberação não é um aspecto negligenciável na construção política, muito menos para Estados periféricos com recursos escassos, gradualmente descolonizados e de passado autoritário recente. É no processo deliberativo que se conhecem visões, confrontam-se opiniões, aproximam-se burocracias e grupos de interesse, comunicam-se chefes de Estado e ministérios e constroem-se alian- 
ças. Todos esses processos foram dinamizados e ganharam maiores chances de estabilidade e permanência com as organizações regionais analisadas. A deliberação permite, ademais, uma maior porosidade dessas instâncias a núcleos decisórios nacionais diferentes dos ministérios de relações exteriores, porque difunde informação e pode gerar transparência. Pode também contribuir, no longo prazo, para o aumento do escrutínio popular sobre temas de política externa. Trata-se, enfim, de um processo regional limitado e que não atingiu todos os objetivos declarados pelos governos progressistas, mas que não é desprovido de significados e de resultados que apontam na direção do diálogo, da aproximação e da democracia, diferentemente de outros momentos históricos.

\section{Referências}

Albin, C. (2003). Negotiating International Cooperation: Global Public Goods and Fairness. Review of International Studies, 29 (3), 365-85.

Amorim, C. (2010). Brazilian Foreign Policy under President Lula (2003-2010): an overview. Revista Brasileira de Política Internacional, 53 (número especial), 214-40.

Amorim, C. (2011) Uma visão brasileira do panorama estratégico global. Contexto Internacional, 33 (2), 265-75.

Amorim, C. (2014). Início de uma política externa altiva e ativa. In G. Maringoni, G. R. Schutte \& G. Berron (Ed.), 2003-2013: uma Nova Política Externa (pp. 31-51), Tubarão: Copiart.

Arnold, C. (2016). Empty Promises and Nonincorporation in Mercosur. International Interactions, 43 (4), 643-67.

Barros, F. (2011). Redes e participação social em campos políticos da cooperação internacional - a experiência brasileira. Revista Sociedade e Estado, 26 (2), 301-27.

Bianculli, A. \& A. Hoffmann (Ed.) (2016). Regional Organizations and Social Policy in Europe and Latin America: a space for social citizeship? London: Palgrave Macmillan.

Bizzozero, L. (2011). América Latina a inicios de la segunda década del siglo XXI: entre el regionalismo estratégico y la regionalización fragmentada. Revista Brasileira de Política Internacional, 54 (1), 29-43.

Borda, S. (2012). Desafios y oportunidades de la Unión de Naciones Suramericanas. Buenos Aires: CRIES.

Botto, M. (2011). ¿Qué nos enseñan los 20 años del Mercosur? Nueva Sociedad, 232, $17-25$.

Botto, M. (2013). Integración regional y actores subnacionales. El caso del Mercosur. Temas y Debates, 25, 83-106.

Botto, M. (2017). El Mercosur y sus crisis: análisis de interpretaciones sobre el fracaso de la integración regional sudamericana. Estado E Comunes, 2 (5), 155-76. 


\section{Clarissa Franzoi Dri y Tiago Mocellin Pittas}

Briceño-Ruiz, J. (2010). From the South American Free Trade Area to the Union of South American Nations: The Transformations of a Rising Regional Process. Latin American Policy, 1 (2), 208-29.

Burges, S. (2008). Consensual hegemony: theorizing Brazilian foreign policy after the Cold War. International Relations, 22 (1), 65-84.

Burges, S. (2015). Revisiting consensual hegemony: Brazilian regional leadership in question. International Politics, 52 (2), 193-207.

Cervo, A. (2003). A política exterior: de Cardoso a Lula. Revista Brasileira de Política Internacional, 46 (1), 5-11.

Cervo, A. \& A. Lessa (2014). O declínio: inserção internacional do Brasil (20112014). Revista Brasileira de Política Internacional, 57 (2), 133-51.

Chagnollaud, D. (1996). Introduction à la politique. Paris: Seuil.

Costa, O., C. Dri \& S. Stavridis (Ed.) (2013). Parliamentary Dimensions of Regionalization and Globalization: The Role of International Parliamentary Institutions. London: Palgrave Macmillan.

Covarrubias, A. (2016). Containing Brazil: Mexico's Response to the Rise of Brazil. Bulletin of Latin American Research, 35 (1), 49-63.

Culpi, L. \& A. Pereira (2016). The Argentine Role in the Promotion of Migration Policy in Mercosur (1991-2014). Fédéralisme Régionalisme, 16.

Dabène, O. (2016a). The contingency of agenda setting in the Union of South American Nations (UNASUR), Em S. Saurugger e F. Terpan (Ed.) Crisis and Institutional Change in Regional Integration (pp.117-135). London: Routledge.

Dabène, O. (2016b), Multilayered summitry and agenda interaction in South America, in G. Mace, J. Thérien and D. Tussie (org.) Summits Ẽ Regional Governance: The Americas in Comparative Perspective (pp. 30-51). New York: Routledge.

Dri, C. (2014). La construction du Parlement du Mercosur: démocratie et régionalisme en Amérique latine. Luxembourg: Larcier.

Dubé, S. \& C. Thiers (2017). Social Group Dynamics and Patterns of Latin American Integration Processes. Revista de Estudios Sociales, 60, 25-35.

Faria, C. A. \& C. Paradis (2013). Humanism and solidarity in Brazilian foreign policy under Lula (2003-2010): theory and practice. Brazilian Political Science Review, 7 (2), 8-36.

Flemes, D. \& R. Castro (2016). Institutional Contestation: Colombia in the Pacific Alliance. Bulletin of Latin American Research, 35 (1), 78-92.

Flemes, D. \& L. Wehner (2015). Drivers of strategic contestation: The case of South America. International Politics, 52 (2), 163-77.

Gardini, G. L. (2007). Who invented Mercosur? Diplomacy and Statecraft, 18(4), 805-30.

Gardini, G. L. (2015). Towards modular regionalism: the proliferation of Latin American cooperation. Revista Brasileira de Política Internacional, 58 (1), 210-29.

Garzón, J. (2015). Multipolarity and the Future of Regionalism: Latin America and Beyond. GIGA Working Paper Series, 264, 1-32. 
Gil, L. \& D. Paikin (2013). Mapa de la Integración Regional en América Latina: Procesos e instituciones. Nueva Sociedad Análisis, 1-34.

Herrero, M. (2017). Hacia una Salud Internacional Sur-Sur: deudas y desafíos en la agenda regional. Ciência Ẽ Saúde Coletiva, 22 (7), 2169-74.

Inge, K., P. Conceição, K. Le Goulven \& R. Mendoza (Ed.) (2003). Providing Global Public Goods: Managing Globalization. New York: Oxford University Press.

Inge, K., I. Grunberg \& M. Stern (Ed.) (1999). Global public goods: international cooperation in the 21st century. New York: Oxford University Press.

Jenne, N \& L. Schenoni (2015). Latin American declaratory regionalism: An analysis of presidential discourse (1994-2014). European Union Institute Working Paper RSCAS 2015/53, 1-17.

Kraphol, S., K. Meissner \& J. Muntschick (2014). Regional powers as leaders or rambos? The ambivalent behaviour of Brazil and South Africa in Regional Economic Integration. Journal of Common Market Studies, 52 (4), 879-95.

Lambert, P. (2016), The Myth of the Good Neighbour: Paraguay's Uneasy Relationship with Brazil. Bulletin of Latin American Research, 35 (1), 34-48.

Lazarou, E. \& B. Luciano (2015). Regionalism as an Instrument: Assessing Brazil's Relations with its Neighbourhood. Global Society, 29 (3), 390-408.

Legler, T. (2013). Post-hegemonic Regionalism and Sovereignty in Latin America: Optimists, Skeptics, and an Emerging Research Agenda. Contexto Internacional, $35(2), 325-52$.

Lima, M. R. (2005). A política externa brasileira e os desafios da cooperação Sul-Sul. Revista Brasileira de Política Internacional, 48 (1), 24-59.

Lima, M. R. (2013), Relações Interamericanas: a nova agenda sul-americana e o Brasil. Lua Nova, 90, 167-201.

Lima, M. R., M. A. Garcia \& V. Pomar (2014). Avanços, impasses e desafios da integração. Em G. Maringoni, G. R. Schutte \& G. Berron (Ed.), 2003-2013: uma Nova Política Externa (pp. 81-120), Tubarão: Copiart.

Malamud, A. (2011a). A Leader without Followers? The Growing Divergence between the Regional and Global Performance of Brazilian Foreign Policy. Latin American Politics and Society, 53 (3), 1-24.

Malamud, A. (201 1b). La política externa de Dilma Rousseff: ¿menos de lo mismo? Iberoamericana, 11(41), 174-79.

Malamud, A. (2013). Overlapping regionalism, no integration: conceptual issues and the Latin America experiences. European Union Institute Working Paper RSCAS 2013/20, 1-12.

Malamud, A. (2016). A Few Non-Conclusive Toughts about Foreign Policy and Social Demands. Contexto Internacional, 38 (1), 503-16.

Malamud, A \& G. L. Gardini (2012). Has regionalism peaked? The Latin American quagmire and its lessons. International Spectator, 47 (1), 116-33. 


\section{Clarissa Franzoi Dri y Tiago Mocellin Pittas}

Maringoni, G., G. Schutte \& G. Berron (2014). Grupo de Reflexão sobre Relações Internacionais. Em G. Maringoni, G. R. Schutte \& G. Berron (Ed.), 2003-2013: uma Nova Política Externa (pp. 3-6), Tubarão: Copiart.

Medeiros, M. (2000). La genèse du Mercosud. Paris: L'Harmattan.

Medeiros, M. \& C. Dri, (2013). Which Brazilian Policy for regionalism? Discourse and institutional development in Mercosur. Estudios Internacionales, 45 (175), 41-61.

Medeiros, M., I. Meunier \& M. Cockles (2015). Processos de Difusão Política e Legitimidade no Mercosul: Mimetismo Institucional e Mecanismos de Internalização de Normas Comunitárias. Contexto Internacional, 37 (2), 537-70.

Medeiros, M. \& M. Saraiva (2009). Os Atores Subnacionais no Mercosul: o caso das papeleras. Lua nova, 78, 77-108.

Medeiros, M., A. Teixeira Jr. \& E. Reis (2017). Cooperação para autonomia? Explicando o paradoxo da política externa brasileira para a Unasul. Revista de Sociologia e Política, 25 (61), 97-123.

Mesquita, R. (2016), The hegemonic hermano: South American collective identity and Brazilian regional strategy, Canadian Journal of Latin American and Caribbean Studies, DOI: 10.1080/08263663.2016.1182691.

Meunier, I. \& M. Medeiros (2013). Construindo a América do Sul: Identidades e Interesses na Formação Discursiva da Unasul. Dados, 56 (3), 673-712.

Nolte, D. (2013). Latin America's New Regional Architecture: Segmented Regionalism or Cooperative Regional Governance? Paper presented at the XXXI International Congress of the Latin American Studies Association.

Nolte, D. (2016). Regional Governance from a Comparative Perspective, Em V. M. González-Sánchez (Ed.), Economy, Politics and Governance Challenges ( $p p$. 1-16). New York: Nova Science Publishers.

Nolte, D. \& N. Comini (2016). UNASUR: Regional Pluralism as a Strategic Outcome. Contexto Internacional, 38 (2), 545-65.

Palma, L. (2016). Empoderamento econômico da mulher no âmbito do Mercosul: das reuniões especializadas ao Programa Ellas Hacen. Revista de Iniciação Científica em Relações Internacionais, 3 (6), 35-57.

Queiroz, L. \& L. Giovanella (2011). Agenda regional da saúde no Mercosul: arquitetura e temas. Revista Panamericana de Salud Pública, 30 (2), 182-88.

Racovschik, M. \& C. Raimundi (2016). ¿Fin de ciclo o paréntesis en la Región? Balance de la última década y reflexiones sobre el nuevo escenario para el MERCOSUR. Buenos Aires: Flacso.

Riggirozzi, P. (2010). Region, regionness and regionalism in Latin America: Towards a new synthesis. Red Latinoamericana de Política Comercial, Working Paper 130.

Riggirozzi, P. (2015a). UNASUR: construcción de una diplomacia regional en materia de salud a través de políticas sociales. Estudios Internacionales, 181, 29-50.

Riggirozzi, P. (2015b), Regionalism, activism, and rights: new opportunities for health diplomacy in South America. Review of International Studies, 41 (2), 407-28. 
Riggirozzi, P. \& D. Tussie (Ed.). (2012). The Rise of Post-Hegemonic Regionalism: the case of Latin America. London: Springer.

Rojas, F. (2010). La Comunidad de Estados Latinoamericanos y Caribeños: ¿Una Opción Viable para Consolidar el Multilateralismo Latinoamericano? Foreign Affairs Latinoamérica, 10 (3), 1-8.

Rojas, F. (2012). La Celac y la integración latinoamericana y caribeña: Principales claves y desafíos. Nueva Sociedad, 240, 16-27.

Russel, R. \& J. Tokatlian (2016). Contemporary Argentina and the Rise of Brazil. Bulletin of Latin American Research, 35 (1), 20-33.

Sanahuja, J. A. (2008). Del "regionalismo abierto" al "regionalismo post-liberal": crisis y cambio en la integración regional en América Latina. Em L. Martínez, L. Peña \& M. Vazquez (Ed.). Anuário de la integración regional de América Latina y el Gran Caribe (pp. 11-54). Buenos Aires: CRIES.

Sanchez, M. (2004). Pontos críticos da participação da sociedade civil no Mercosul. Texto para Discussão, Escola de Direito FGV São Paulo, 1-35.

Sarti, I., J. R. Martins, M. Lessa \& G. Carvalho (Ed.) (2014). Os desafios da integração sul-americana: autonomia e desenvolvimento. Rio de Janeiro: Letra e Imagem.

Schenoni, L. \& E. Actis (2014). Argentina y Brasil: una unipolaridad regional con sesgo económico. Revista $S A A P, 8$ (1), 207-35.

Scott, B. (2007). Why Cooperate? The Incentive to Supply Global Public Goods. New York: Oxford University Press.

Seitenfus, R. (1989). A cooperação argentino-brasileira: significados e perspectivas. Lua Nova, 18, 107-26.

Serbin, A. (2013). Atuando sozinho? Governos, sociedade civil e regionalismo na América do Sul. Lua Nova, 90, 297-327.

Vaillant, M. (2014). Evolución del Mercado Común del Sur (MERCOSUR): Relaciones Intrarregionales. Caracas: SELA.

Vaz, A., A. Fuccille \& L. Rezende (2017). UNASUR, Brazil, and the South American defence cooperation: A decade later. Revista Brasileira de Política Internacional, $60(2), \mathrm{e} 012$.

Vazquez, M \& D. Perrotta (2012). Paz, democracia e integración regional en América del Sur: Visibilizando los logros políticos, sociales y culturales del MERCOSUR y de la integración regional en América Latina y el Caribe . Buenos Aires: Identidad Mercosur.

Veiga, P. \& S. Rios (2007). O regionalismo pós-liberal na América do Sul: origens, iniciativas e dilemas. Série Comercio Internacional, 82, Santiago, CEPAL.

Ventura, D., J. Onuki \& M. Medeiros (2012). Internalização das normas do MERCOSUL. Série Pensando o Direito, 45, Brasília, Ministério da Justiça.

Vigevani, T. \& G. Cepaluni (2007). A política externa de Lula da Silva: a estratégia da autonomia pela diversificação. Contexto Internacional, 29 (2), 273-335.

Wehner, L. (2015). Role Expectations as Foreign Policy: South American Secondary Powers' Expectations of Brazil as a Regional Power. Foreign Policy Analysis, 11 (4), 435-55. 
Weiffen, B. (2017). Institutional Overlap and Responses to Political Crises in South America. Em M. Suarez, R. Villa e B. Weiffen (Ed.) Power Dynamics and Regional Security in Latin America (pp. 173-197). Basingstoke: Palgrave Macmillan.

Weiffen, B., L. Wehner \& D. Nolte (2013). Overlapping regional security institutions in South America: The case of OAS and UNASUR. International Area Studies Review, 16 (4), 370-89.

\title{
Palavras-chave
}

Integração regional — América Latina — Mercosul — cooperação — política externa brasileira

\section{Keywords}

Regional integration - Latin America - Mercosur - cooperation - Brazilian foreign policy

\begin{abstract}
This paper intends to offer a panorama of Brazil's cooperative relations with her neighbors and to propose an assessment of regional integration focused on political and social dimensions. In order to do so, norms emanating from decisional organs of Mercosul, Unasur and CELAC since their creation until 2015 were categorized, so that we could verify the number of agreements in each sector. The most recurrent topics were selected for qualitative analysis seeking to unveil Brazilian regional strategies. The conclusion points out to the presence of a deliberative and instrumental regionalism. Results show that Brazil has instrumentalized regional cooperation in order to reinforce her international leadership. Nevertheless, integration beyond trade and economics, which was the goal announced by left-wing governments, was partially achieved and did allow for the building of a structured regional dialogue in new areas.
\end{abstract}

